\title{
Electro-optical remote sensing systems program at MIIGAiK
}

\section{Vladimir Solomatin, Yuri Yakushenkov}

Vladimir A. Solomatin, Yuri G. Yakushenkov, "Electro-optical remote sensing systems program at MIIGAiK," Proc. SPIE 3190, Fifth International Topical Meeting on Education and Training in Optics, (8 December 1997); doi: $10.1117 / 12.294399$

Event: Fifth International Topical Meeting on Education and Training in Optics, 1997, Delft, Netherlands 
Electro-optical remote sensing systems program at MIIGAiK

Uladimir A. Solomatin and Yuri G. Yakushenkov

Moscow State University of Geodesy and Cartography (MIIGAiK)

MIIGAiK Optical Department, Gorokhousky by-str.,4, Moscow, Russia

\section{ABSTRACT}

Premises of the course of Electro-0ptical Remote Sensing Systems (EORSS) creation are discussed. Structure and some particularities of the course are presented.

Keywords: electro-optical system, remote sensing, curriculum, signal description and transformation

\section{INTRODUCTION}

The course "Electro-Optical Remote Sensing Systems" has been organized at MIIGAiK for a new specialization "Natural Resources Researching" at the beginning of 1980s. The course program is based on fundamental physical and mathematical training.

The main sections of the course are:

- methods of signals and signal processing description for EORSS:

- scheme-technical and element base of EORSS;

- general structure arranging principles for various EORSS (for ecological monitoring. Earth's natural resourses researching, operative seismic information processing, main climatic-forming processing, et al.).

\section{SOME PREMISES OF THE COURSE CREATION}

There were the next main circumstances of the course producing in our University:

- The course has been based on a series of fundamental disciplines"Mathematics", "Physics", "Information Theory", "Physical Optics", "Applied Optics". "Electronics". So it was possible to set forth the course at a proper scientific base;

- Remote sensing is a very extensive scientific and technical sphe- 
re and there are large difficulties of its curriculum composing. Moreover the curriculum must be useful for future engineers, managers, and consumers at the same time;

- Text-books for EORSS design and exploitation were absent:

- EORSS element base is extended and improved continuously. For this reason it was necessary to avoid some ordinary information accumulating for the course learning;

- Modern EORSS are very complex and can't be often given for students'training. So special emphasis was placed upon construction of EORSS mathematical models, and physical interpretation of the dates obtained with the help of EORSS;

- MIIGAiK has accumulated the significant experience in series of space EORSS development.

\section{STRUCTURE AND SOME PARTICULARITIES OF THE COURSE}

The course "Electro-Optical Remote Sensing Systems" includes the following main section:

- Methods of Signal and Signal Processing Description for EORSS;

- Scheme-Technique and Element Base of EORSS;

- Principles of Typical EORSS Construction.

Methods of signal description and transformation are given in the first section. A field of radiation is considered as a source of information transferred by the optical multidimensional signal. It may be singled out energy, spectral, temporal, spatial, polarization information depending on concrete analysis or design nature. Linear transformations, spectral, spatial, and temporal filtering, modulation and demodulation, sampling, scanning are considered to be the main methods of signal transformation. Grafic and analytic form of Fourier-transformation is used widely in the section.

This form has a number of advantages namely:

- Fourier-analysis is unified for periodic and unperiodic signals;

- it is compact and graphic form for recording:

- it permits transformation checking and avoiding of gross mistake.

The second section of the course is "building" foundation of EORSS. The students study optical radiators and detectors, typical optical elements and systems, modulators, filters, scanning devices, etc. 
The third section is EORSS "architecture". Principles of construction, methods of the main EORSS parameter design, and system analysis of EORSS are studied here. All the EORSS are separated into some parts:

- Electro-Optical Radiometers.

- Television Systems,

- Thermovision Systems.

- Electro-Optical Spectrometers.

- Multispectral Scanners and Uideospectrometers,

- Lidars,

and the other ones. General signs of each part are not only structural schemes but methods of design. Besides the section includes a number of concrete EORSS description.

Principles of arranging laboratory practice for the course are stated in the other paper submitted to this Meeting ( "Optical and Electro-Optical Laboratory Practice for Undergraduates" by Y.B. Parvulyusov, U.A. Ilyuhin, U.A. Solomatin, and Y.G. Yakushenkov).

The course is provided with the monograph "Electro-Optical Devices for Natural Resources Researching" (by A.S.Elizarenko, U.A.Solomatin, Y.G. Yakushenkov. Ed.by Y,G. Yakushenkov. Moscow, Nedra, 1984) and the text-book "Electro-Optical Devices for Remote Sensing" (by U.P.Savinykh and U.A.Solomatin. Moscow, Nedra, 1995). 